\section{Commentary: Navigating the pitfalls in the surgical management of pseudoxanthoma elasticum}

\author{
Homare Okamura, MD, PhD
}

Anderson and colleagues ${ }^{1}$ reported the management of severe symptomatic aortic stenosis (AS) and pseudoxanthoma elasticum (PXE) in a 61-year-old man. They successfully performed minimally invasive surgical aortic valve replacement with careful perioperative planning. PXE is a rare autosomal-recessive disease caused by mutations in the ABCC6 gene and affects the connective tissues. PXE is phenotypically characterized by the fragmentation of elastic fibers and ectopic mineralization in the skin, retina, and arterial walls. ${ }^{2}$ In the cardiovascular system, PXE predominantly affects small-sized and medium-sized arteries, and aneurysms, stroke, and stenosis of medium-sized arteries and the aorta have been reported. ${ }^{3}$ Although the association between PXE and AS is unclear, ${ }^{4}$ cardiac surgeries in patients with PXE, especially those who require cardiopulmonary bypass (CPB), necessitate careful surgical planning.

Reliable intraoperative hemodynamic monitoring is crucial in cardiac surgery. In the authors' case, blood pressure monitoring using bilateral radial arteries was unsuccessful due to diffuse atheromatous plaques, and an ulnar arterial line was placed. Even with the successful arterial line, the accuracy of monitoring is of concern because the artery proximal to the monitoring site can be stenotic. Therefore, preoperative evaluation of arteries using contrast-enhanced computed tomography might be useful. Furthermore, recognizing the differences in the blood pressure between the central and peripheral arterial lines before weaning off $\mathrm{CPB}$ would also be

\footnotetext{
From the Department of Cardiovascular Surgery, Nerima Hikarigaoka Hospital, Tokyo, Japan.

Disclosures: The author reported no conflicts of interest.

The Journal policy requires editors and reviewers to disclose conflicts of interest and to decline handling or reviewing manuscripts for which they may have a conflict of interest. The editors and reviewers of this article have no conflicts of interest.

Received for publication July 25, 2021; revisions received July 25, 2021; accepted for publication July 30, 2021; available ahead of print Aug 6, 2021.

Address for reprints: Homare Okamura, MD, PhD, 2-11-1 Hikarigaoka, Nerima-Ku, Tokyo 179-0072, Japan (E-mail: homareo@jadecom.jp).

JTCVS Techniques 2021;9:42-3

2666-2507

Copyright (C 2021 The Author(s). Published by Elsevier Inc. on behalf of The American Association for Thoracic Surgery. This is an open access article under the CC BY-NC-ND license (http://creativecommons.org/licenses/by-nc-nd/4.0/).

https://doi.org/10.1016/j.xjtc.2021.07.028
}

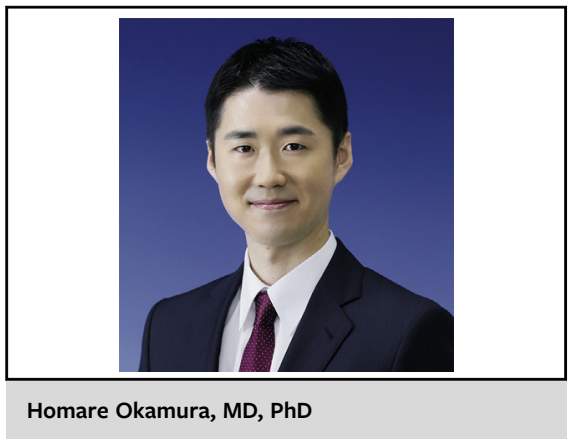

CENTRAL MESSAGE

Preoperative evaluation of the arteries, careful surgical planning, and attention to postoperative anticoagulation are crucial in patients with pseudoxanthoma elasticum.

helpful in precisely estimating the central blood pressure postoperatively.

Intraoperatively, several points need to be considered. In selecting the site of arterial cannulation for CPB, epiaortic ultrasonography is very effective in identifying sites without atherosclerotic plaques, as reported by the authors. Furthermore, the authors reported that the calcified aortic valve was fragile and could be easily broken with handling. Although transcatheter aortic valve replacement was not chosen because of the patient's age and extensive calcification in the peripheral arteries, the crumbly aortic valve in PXE also raises concerns of embolism during transcatheter aortic valve replacement; therefore, surgical aortic valve replacement might be safer in patients with AS and PXE. Weakness of the vascular wall has also been reported in PXE, and the vessels for surgical grafts should be carefully chosen in cases of coronary artery bypass grafting. ${ }^{3}$ The saphenous vein may be preferred over the internal mammary artery in such cases.

Management of postoperative anticoagulation is another important issue. Several investigators have raised concerns about thromboembolism associated with enhanced ectopic mineralization caused by warfarin, as reported by the authors. Although the adverse clinical effects of warfarin in patients with PXE have not yet been established in humans, surgeons need to acknowledge the possibility of enhanced ectopic mineralization due to 
warfarin and carefully select the artificial valve as well as the postoperative anticoagulation strategy. Preference for bioprostheses over mechanical valves might be justified for valve replacement in patients with PXE, including young patients.

The authors have highlighted the perioperative management of PXE with their successful report, and surgeons need to thoroughly understand the peculiarity of this rare inherited disease.

\section{References}

1. Anderson D, Gustafson J, Tseng EE. Minimally invasive surgical aortic valve replacement in setting of pseudoxanthoma elasticum. J Thorac Cadiovasc Surg Tech. 2021;9:36-9.

2. Rashdan NA, Rutsch F, Kempf H, Váradi A, Lefthériotis G, MacRae VE. New perspectives on rare connective tissue calcifying diseases. Curr Opin Pharmacol. 2016;28:14-23.

3. Germain DP. Pseudoxanthoma elasticum. Orphanet J Rare Dis. 2017;12:85.

4. Prunier F, Terrien G, Le Corre Y, Apana AL, Biere L, Kauffenstein G, et al. Pseudoxanthoma elasticum: cardiac findings in patients and Abcc6-deficient mouse model. PLoS One. 2013;8:e68700. 